\title{
The Dialectics of Hinglish: A Perspective
}

\author{
Nidhi NEMA \\ Bhopal School of Social Sciences \& Affiliated Barkatullah University \\ E-mail: nidhinema@yahoo.com
}

\section{Jagtar Kaur CHAWLA}

Bhopal School of Social Sciences \& Affiliated Barkatullah University

E-mail: jagtar.kaur.chawla@gmail.com

\begin{abstract}
In India, the phenomenon of Hinglish has rapidly emerged from being a fashionable style of speech to a significant force instrumental in bringing about a major paradigm shift in social demography. Globalization and economic liberalization has served as catalysts to amplify this uniform communication code, which is currently blurring the linguistic barriers in a country speaking 780 dialects. Hinglish is redefining the cultural conventions in marketing/advertisement, Bollywood, and communication styles present in social media and the Internet. Its claim to be a proper language is substantiated by its acknowledgement on prestigious literary forums. While the concept is welcomed by both the marketplace and the masses as a beneficial symbiotic experience, it has also left the stakeholders of standard language, both Hindi and English, fretting and fuming. Amidst all the celebrations and concerns, the corpus of Hinglish is constantly widening and evolving because it is has been internalized, and not imposed, by the society as its own creation. The language accommodates diversity, lends flexibility, and suits the temperament of modern India. This paper studies how Hinglish has managed to seep into the very fabric of Indian society, restructuring the governing norms and practices. The paper also attempts to reflect how Hinglish is much more than just a language hybrid.
\end{abstract}

Keywords: Hinglish, English, India, globalisation

\section{Introduction}

The heterogeneous nature of Indian reality and rich linguistic diversity compels us to be multi-lingual, and switching between two or more languages comes naturally to us. The symbiotic relationship between Hindi and English is the result of the multicultural and multidimensional nature of Indian society and its age-old linguistic habit of juxtaposing two or more dialects together in regular speech, shifting from one discursive context to another. The two languages are so inexorably intertwined with each other through shared history that English predication looks like a natural ending to a Hindi subject and vice versa. This relationship has now gone to a different level as Hindi and English now harmoniously cohabit in a common space called Hinglish.

The emergence of new (socio-linguistic) concepts is preceded by a set of contributory factors and a history of causative circumstances. In order to understand the etymology of any given linguistic variant, it is important to analyze the reasons behind its coming into existence, as well as its usage and scope. In the same way, to 
propose an examination of the conceptual framework of this newer field called Hinglish, it is important to unfold the (a) conditions that constituted the groundwork for the emergence of Hinglish (b) the observable, structural properties of Hinglish, and (c) the manner in which the users perceive and respond to Hinglish.

The working of a hybrid language involves restructuring and reshuffling of two or more languages so as to make them mutually intelligible, compatible and accessible to the target users. Code mixing and code switching happen naturally, resulting in an expansion of lexical parameters. Hinglish, a relatively new occurrence in India, negotiates in the spheres of both Hindi and English operating as a beneficiary mediator. It freely borrows from both fields and creates a unique borderline that is flexible, variable and ever expanding. Therefore, its semantic base is constantly in a state of flux, susceptible to latest trends and subjective to its users. The process of meaning making is ongoing, with new phrases and idioms being coined on almost a daily basis, making the field of Hinglish very dynamic. The other contributory factor is the growing range of human experience or knowledge that is directly responsible for the expansion of the domains of reference and conception in terms of physical, psychological, inferential, social and dialectical. Fast changing technology and consumer friendly products such as mobile devices, the Internet, and social media have played a catalytic role in nourishing and expanding the role of this synthesized language.

Colonization marks the beginning of the interface between Hindi and English in India. In a bid to establish their economic and political domination, crossing the language barrier became imperative to the British colonizers. The inclusion of Hindi words in English syntax was necessary for filling the socio-cultural gaps between the colonizers and colonized. It manifested in the form of highly asymmetric code-mixing (mixing of Hindi words in an English sentence) and fragmented use of Hindi used mostly for carrying out administrative and mercantile affairs, haphazard superficial social interactions, and downward communication with servants. Hence words like sahib/mem sahib, blighty, pundit, mufti, maharajah, nabab, guru, gora, bucksheesh, firinghee, which have now become a part of the English vocabulary, were originally used by the English with the intent to set the new social hierarchy and demarcate the social status. Examples of British register of that period can be found in Rudyard Kipling's 1892 poem Gunga Din. ${ }^{1}$

\author{
It was "Din! Din! Din! \\ You limping lump o' brick-dust, Gunga Din! \\ Hi! slippy hitherao! \\ Water, get it! Panee lao! \\ You squidgy-nosed old idol, Gunga Din!" \\ It was "Din! Din! Din!
}

\footnotetext{
${ }^{1}$ The poem is a rhyming narrative from the point of view of an English soldier in India, about an Indian water-bearer (a "Bhishti") who saves the soldier's life but is soon shot and killed. In the final three lines, the soldier regrets the abuse he dealt to Din and admits that Din is the better man of the two for sacrificing his own life to save another. The poem was published as one of the set of martial poems called the Barrack-Room Ballads. (Source: Wikipedia)
} 
You 'eathen, where the mischief 'ave you been?

You put some juldee in it,

Or I'll marrow you this minute,

If you don’t fill up my helmet, Gunga Din!” (Kipling 1920)

Imperialism ended in India at the middle of the $20^{\text {th }}$ century, and the rulers took away with them several lexical souvenirs like Bungalow, Avataar, Bazaar, Bandanna, Caravan, Dekko, Jungle, Cooly, Kedgeree, Mogul, Jungle, Veranda, Shampoo, Thug, Punch (as in Drinks), Cheetah, Hullabaloo, Loot, Pukka, Yoga. These words gained acceptance as common parlance in English dictionaries like Hobson-Jobson ${ }^{2}$ (H. Yule/ A.C. Burnell 1903). Besides these words, there were other coinages made specifically for the Indian context. Words like Collector, Boxwallah, Balcony, Charpoy, Competition-Wallah, Civilian, Compound, Factory, Fetish, Indigo, VIP, First-Class have had different connotations in Indian English from that of any other dialect of English. Though the British were hated, the sentiments did not extend to their language and even after the departure of the colonizers their language was not just retained but also internalized as the second official language of the country. The English language experienced a decolonization phase in India around the 1970s after the departure of authentic 'Convent' or the All-English medium educational institutes run by English Missionaries and Irish nuns. Though English still held its elite status in the socio-cultural hierarchy, the 'propah Queen's English' witnessed the sneaking in of the dominant vernacular Hindi in its well-protected institutions. The sanctity and decorum of pure English grammar and syntax was being risked outside the campus and switching the codes between Hindi and English was seen as rebel and fashionable. Amit Choudhary's protagonist of his short story 'Prelude to an Autobiography,' who is a by-product of the 'convent,' says, "speaking pucca English was slightly ridiculous and was supposed to be goody-goody." (A.R. Gera 2013) ${ }^{3}$ This was the time when being up-market became synonymous with stiff and 'different' or unrelatable for the anglicized upper class Indian youth. In an attempt to look not-so-English and to stop looking 'exclusivist,' the products of these convent schools started using different permutations and combinations of English with desi dialect.

The third phase in Hinglish started in the 1990s with the wave of globalization and augmented privatization in India. As the doors of the gigantic market of India opened for the world, the former witnessed major economic up-turns that played a

\footnotetext{
${ }^{2}$ Hobson-Jobson is a unique work of maverick scholarship. Compiled in 1886 by two India enthusiasts, it documents the words and phrases that entered English from Arabic, Persian, Indian, and Chinese sources - and vice versa. Described by Salman Rushdie as 'the legendary dictionary of British India' it shows how words of Indian origin were absorbed into the English language and records not only the vocabulary but the culture of the Raj. It encompasses aspects of the history, trade, peoples, and geography of Asia in entries that are at once authoritative and playful. Like the Oxford English Dictionary, HobsonJobson included illustrative quotations that were drawn from a wide range of travel texts, histories, memoirs, and novels, creating a canon of English writing about India. The definitions frequently slip into anecdote, reminiscence, and digression, and they offer intriguing insights into Victorian attitudes to India and its people and customs. (Source: OUP Online)

${ }^{3}$ Line taken from Amit Chaudhary's short story 'Prelude to an Autobiography' qtd in Anjali Gera Roy's The Politics of Hinglish
} 
significant role in bringing about a major paradigm shift in all the segments of society. Within a short span of time, many changes took place in a cascading fashion: the influx of MNCs, increased outsourcing/insourcing, the IT revolution, the Indian film industry (Bollywood) going global and finding a new audience base in the enlarged NRI group, the boom of satellite television, new and improved FM radio, and an increased demand for Indian professionals abroad. All of these factors not just impacted the economy but also altered the socio-cultural dynamics of Indian society and led to a sort of re-arrangement and realignment of the general mindset. The composite effect of all these factors was a newly defined mass culture, driven largely by a consumer market, possessing its own set of conventions, practices and dialect. Hinglish, being a recent entry and also having gained fair degree of acceptance, became the popular voice of the changed Indian culture. It was conducive to the temperament of the market as well as society. The language quickly gained a wider and deeper currency because:

- The English speaker found it fashionable while the Hindi speaker found it aspirational

- Marketing slogans written in Hinglish gained wider access and stronger acceptance among consumers

- The code mixing and code switching had an instant connection with the youth who found a new text-speak in Hinglish

- It offered an opportunity to experiment with the regular language and make the conversation more vibrant and engaging

- Growing internet usage and social media demanded a common linguistic code Today, Hinglish is 'the' language of the Indian youth and it occupies a space everywhere they are - mobile devices, social networking, the internet, the cinema and other media. This phenomenon, propelled mainly by market forces and fueled by a growing number of internet users, has gained epistemic status. It has become an integral part of the mainstream psyche. No longer regarded as impure or frivolous but rather pragmatic, effective and relevant, Hinglish has captured the imagination of a vast demography like nothing else before and has emerged as the informal voice of India.

\section{Indian English and Hinglish}

"There is Indian English with its non-standard variety of English reflecting Indian "vernacular" patterns, while Hinglish is a new hybrid," says Anjali Gera Roy in her article "The Politics of Hinglish" (A.R. Gera 2013). However, in general, the label of Hinglish is used as a cover term for Indian English and its dialectic variations. But for the purpose of this study, we would treat them as separate entities and would consider Hinglish to be an offshoot of Indian English.

Indian English is a vibrant arena of semantics wherein the English has internalized the national specifics of politics, society and culture. Phonological variations depend on the regional or local speeches and accents/stress patterns vary from place to place. This English is quite paradoxical in nature as in it not only preserved the colonial 
heritage but also decolonized it by customizing the language to fit into the postcolonial Indian setup. It has helped to remove the tag of 'alien' or foreign from the language and has brought it within the access of the common man. It is more culturally regulated and spiced up with a rich dose of local verbs, connotations and denotations. In order to cater to the multilayered demography of India with its varied and unique conceptual system, English had to undergo certain modifications and enhancements taking it a little bit away from regular British English. Though Indian English works on a proper English base and operates within the framework of prescribed standard grammar, it takes several liberties with the syntactic, lexical and phonetic parameters. The following are a few noteworthy examples:

(1) Literal translation of Hindi sentence/phrase: Progressive tense in place of indefinite

Sleep is coming

I'm believing you

She is liking the music

She is here, no?

(2) New coinages for the terms which have no English equivalent:

Votebank (the base of voters), NRI (Non-resident Indian), eve teasing (molesting a girl), tiffin (lunch box), topper (highest scorer), airdash (to rush for an emergency), English-knowing (one who knows English language), matrimonial (an ad for marriage), wheatish (light brown complexion) prepone (opposite of postpone), pass out (complete a course), non-veg (meat) mugging up (cramming)

(3) Different words and word ordering:

$\mathrm{He}$ is too good (he is very/extremely good)

We arrived today only (we came today)

He simply won't listen (he would just not listen)

Let's do it tomorrow itself (superfluity for emphasis)

(4) Archaic/Colonial leftovers:

$\mathrm{He}$ is out of station (he is out of the town/city)

I'll take your leave (I'll go now)

I beg your pardon (excuse me)

Do the needful (do what is required)

(5) Superfluity:

Discuss about; reply back; order for; meet with you

(6) Indianized Expressions:

$\mathrm{He}$ is sitting on my head (forcing someone to do something)

It's time you stood on your own feet (to become self dependent)

She is giving me line; I'll take a chance (to try to hit on a person of opposite sex)

That movie was a real time-pass, first class! (to find a movie worth watching)

Hinglish can be defined as a proper blend of Hindi and English with a unique vocabulary and style of its own. As Das prefers to call it, it is a 'pan India's street language' (G. Das 2005) that goes a few steps ahead of Indian English in defying all restrictive parameters as it works on one simple formula, and that is no-formula. Its base can be either Hindi with a smattering of English words or vice versa. The register 
is conditional and keeps changing with the person, setting, emotions and situation formal, informal, serious, humorous- and it yet remains intelligible to the speakers of both the languages. There is limitless scope for experimentation, expansion and a free license to innovation because its semantics are still evolving. Hence, fancy catch phrases, inflectional variants, informal discourses, trendy hook lines, and workable social media speech are all constituted in Hinglish to capture the sensibilities of both language users. Newer concepts are being floated everyday with newer labels to define them. Meaning-making is an ongoing process and media/technology is the chief facilitator in propagation of it. So what qualifies as Hinglish? Here are a few prototypes:

(7) Code switching: switching languages between sentences

I'm going there, dost se milne ke liye (I'm going there, to meet my friend)

Could you please wait? Bas do minute aur! (could you please wait? Just two more minutes!)

Bahot bore ho rahe hain. Let's go out and have fun! (We're getting bored. Let's go out and have fun!)

(8) Code mixing with English Base: mixing lexis of Hindi in an English sentence

$\mathrm{He}$ is creating a tamasha (he is creating a scene)

Let's do it, yaar (let's do it buddy)

You have taken a major panga! (You are in a huge mess!)

He is a pucca idiot (he is a complete idiot)

(9) Code mixing with Hindi base: mixing lexis of English in Hindi Sentence

Mein ticket book karna chahta hoon (I want to book/buy a ticket)

Koi problem hai kya? (Do you have any problem?)

Please, rasta dijiye (Please make way)

Chill maar yaar! Don't get all worked up (relax and take it easy)

(10) Chutneyfied compounds: a word of one language with a prefix or suffix of another

Uncleji, Auntyji, Sirji, Madamji

Schoolon mein Teacheron ko bahot workload hai. (Teachers in schools deal with lot of work)

Don't Darofy just karofy (don't be afraid, just do it)

He is very filmy (he is a film buff/he is dramatic)

Roadein kharab hain, driveron ko problem hogi (roads are damaged, drivers would face problems)

(11) New Connotations: unique trendy coinages/slang words

Short-circuit: to lose it

ATM: Auntie-turned-modern

Stadium: bald having fringe hair

Son-stroke: favoritism towards male child

Would-be: fiancé

Hinglish has been stoked by increasing consumerism and commodification. Hinglish has served as a useful tool to seal the deal successfully between various markets viz commodity, service, media, journalism, arts/culture, and politics. Listed below are 
some of the key role players who are the main contributors to the sustenance and transmission of this new language system.

\section{E-Media/ Internet}

India saw the renaissance of TV entertainment in the 1990s with the influx of various satellite channels like Star TV, Sony, Zee, Colors and hundreds of other entertainment, news and informative channels that transformed the media landscape totally by substituting the ubiquitous state-owned monopoly Doordarshan. The presence of trans-international media houses became acceptable only when they indigenized their content and language to suit the eclectic temperament of the Indian public. The conversational style of news presentation and panel discussions, TV shows with crosscultural content, and video jockeys on music channels with a mish-mash jargon rely heavily on Hinglish as the medium of communication. All of these factors not only essentialized Hinglish on TV but also redefined the mass culture.

Television has been a major role player in national integration and holding intact the essence of the multicultural, multilingual, multiethnic society of India. Today this media wields immense power that is both constructive and destructive. In order to maintain its ever-strengthening sway on the viewing population, it is inevitable for emedia to speak the language of the people. Hinglish, having already struck the right chord with the youth, surfaced as a big instrument to make an instant connection and impact.

The TV shows being aired currently on the youth channels like Channel V, Bindass and MTV are interpolated not just in titles but also in character. These TV shows are catering to a hybrid sensibility and culture of a modern consumer who is both shaping and being shaped by market forces that play a stronger role in modifying parochial traditions, introducing new conventions and practices, and defining familial and individual roles. In comparison to any past change, this rapid paradigm shift redefines societal norms everyday in consonance with the newer realities and changing environments. Newer meanings are being coined by the media to give expressions to newer experiences and Hinglish has assumed the role of a stock supplier. The fact that popular English news channels have switched to Hinglish in order to 'recruit more viewers' for their channels is the reflector of the significance of this language. For instance, Republic TV editor-in-chief Arnab Goswami interviewed Uttar Pradesh Chief Minister Yogi Adityanath in Hinglish. "Bahut bahut congratulations, apne pehle 100 din me jo kiya" (Congratulations on your achievements in your first 100 days).

The verbal jugglery is seen in all its glory on the revamped FM radio stations where bilingual radio jockeys (RJs) engage in casual, informal verbosity in order to exhibit their proficiency in the linguistic domain of Hinglish. In recent years, these radio jockeys seem to have worked out a nuanced hybrid register of their own which they handle in a smoothly entertaining manner. As Radio Mirchi, one of the famous FM channel goes by the refrain 'mirchi sunnewale always khush,' the objective of 'fun' is exhibited in every aspect of content and presentation on radio. The sing-song manner of chatter, their personal approach and quirky attitude finds fuller expression 
through Hinglish, which is the 'official' language of private radio channels today.

Another source of Hinglish penetration is through the World Wide Web or internet media. Born from the IT revolution, i-media such as informative web sites/channels, social networking sites, blogs and other i-resources, control and manipulate the internet user's world: their lifestyles, choices, actions and language. I-media practices and conventions are essentially offbeat, making the Internet a youth centric domain. On these websites, Hinglish is de-standardized, open, uncensored, creative and effervescent. The relationship of Internet and Hinglish is again mutually reinforcing. The Internet plays a pivotal role in increasing the repertoire of the hybrid language by constantly minting and floating the newer tech-jargon and catchy textual connotations. While in return, Hinglish consolidates the position of the medium as a strong influencer of the present generation. The technological grip is being strengthened by Hinglish, which is working to make the media more and more user friendly.

The technical jargon related to mobile technology like recharge, top up, missed call, prepaid-postpaid, SMS, caller tune has also become the basis of the 'hep-lingo,' the abbreviated or condensed style of communication conducted on mobiles, text messages, Facebook and Watsapp. The introduction of Hinglish as one of the language options for keyboard languages in the latest cell phones and laptops highlights the ever-growing importance of Hinglish. Indian sentiments are being expressed through English alphabets on the mobile phones through transliteration. The conversation slides from Hindi to English and vice versa seamlessly and this type of mixed clipped communication has become increasingly more frequent.

\section{Literature}

P.C. Verghese (1971: 103) writes,

The Indian social, cultural and linguistic setup has affected the features of English language as used by the Indian creative writers in English, especially the novelists, and 'Indian English' is only a variety of English whose characteristics stems from the life and culture of the people of India.

IWE (Indian Writing in English) is regarded as one of the voices or variants in which India speaks. Every Indian writer invariably carries the baggage of 'Indianness,' which is embedded in his perceptions of reality and socio-cultural dimensions in the way he contextualizes his aesthetic and linguistic principles. All of these are in a way the indexical features of his Indianness that locate him in his native milieu. The vernacular preferences are inevitable and their resonations can be seen through the linguistic interpolations and syntactic experiments. The text of their works is permeated with Indian themes, thought, concerns and imagery, which can be discerned by paying attention to the textuality. Hence, they are largely responsible for the acculturation of English by adapting it to the Indian perspective.

Indian English Literature has liberally borrowed from the rich vernaculars and their variants to recreate the verisimilitude. It has often incorporated the idiomatic expressions and phraseology used in local dialects so as to give an authentic reflection of the complex Indian reality and its equally layered experience. The process of 
Indianization of English started from the moment the poetic license got transferred to Indian writers with independence. Thus, R. K. Narayan's ${ }^{4}$ Indian stories were told in a very casual, impartial and simple English interspersed with many Hindi and Tamil words that served to infuse the cultural elements of his class and time. A self professed writer of Indianized English, he never attempted to write in Anglo-Saxon as it would have obstructed his textual authenticity and honesty. His expressions like 'it is still paining me...' 'I can't mug up...' 'behave like a rowdy...' are all Indianized.

While writing from the point of view of a typical middle class Indian, Nissim Ezekiel $^{5}$ in "Very Indian Poems in Indian English" contained in Latter Day Psalms exposed the Indian people's faulty use of language. These poems namely "The Patriot", "The Professor" and "Irani Restaurant Instructions" highlighted in a humorous tone the linguistic errors of Indians while speaking English.

"The Patriot," presented in a very light vein an English that contains all the characteristics of Indianness - use of present continuous instead of indefinite and Hindi word order.

I am standing for peace and non-violence.

Why world is fighting fighting

Why all people of world

Are not following Mahatma Gandhi,

I am simply not understanding.

Ancient Indian Wisdom is $100 \%$ correct.

I should say even $200 \%$ correct.

But modern generation is neglecting-

Too much going for fashion and foreign thing (Ezekiel 1982).

'When Empire wrote back,' as per Salman Rushdie, it reflected the voice of the decolonized group that presented a strong claim on the linguistic space shared by English speakers worldwide. Dealing with the issues of fractured identity and racism, Rushdie employed Hinglish liberally in his 1981 Man Booker Prize winning novel Midnight's Children. Arre Baap, ekdum, nasbandi, phu-a-phut, dhoabn, rakshasha, fauz, jailkhana, badmaash, baap-re-baap, pyar kiya to darna kya, zenana, sarpanch, bhel-puri...are few of those expressions that appear in the book without Italics. Some critics find it an interesting attempt to situate the story in the authentic setting of independence, while others find it as nothing more than an attempt to exoticize his story telling. In her Introduction to Rushdie's Midnight's Children: A Book of Critical Readings, Meenakshi Mukherjee sums up Rushdie's attitude :

'Linguistic risks' that Rushdie took with utter abandon, defining them as 'getting away with the use of the mongrel street language of cities, daring to translate idioms and puns

\footnotetext{
4 R.K. Narayan (10 October 1906 - 13 May 2001), full name Rasipuram Krishnaswami Iyer Narayanaswami, was an Indian writer, best known for his works set in the fictional South Indian town of Malgudi. He is one of three leading figures of early Indian Literature in English alongside Mulk Raj Anand and Raja Rao, and is credited with bringing the genre to the rest of the world.

${ }^{5}$ Nissim Ezekiel was an Indian Jewish poet, actor, playwright, editor and art-critic. He was a foundational figure in postcolonial India's literary history, specifically for Indian writing in English.
} 
mediated by no apology, no footnote, no glossary' (M. Mukherjee 2003: 10).

Whatever be the critical viewpoint, Rushdie opened up new avenues for the usage of hybrid Hinglish to comprehend the Indian context and sensibility. It is also seen as the subversive approach of the subaltern to assert itself with zing and sting. Hinglish is justified as an apt vehicle for conveying the modern/postmodern experience and carrying off the layered complexity of contemporary society and man. A more modern writer Shobha De's ' ${ }^{6}$ unapologetic' Hinglish seeks a kind of alliance between the very Indian subject matter, be it films, politics or other issues, and her linguistic choice, ie, English. She uses Hindi words in her pucca English to provide an extra sharpness that can be conveyed only through Hindi vocabulary. Arundhati Roy's postcolonialism and Upamanyu Chatterjee's postmodernism are underscored by inwardness towards contemporary Indian situation, attitude and voice. They are true Indian writers, writing from within India with a microscopic vision on Indian reality. Their Hinglish reflects the attitude of today's anglicized youth who live rather comfortably homogenizing the two languages continuously. Chatterjee's debut novel English August: an Indian Story is in fact a metaphor for the encounter of an upper middle class 'English-knowing' metropolitan man with rather pure 'Hindi-using' interiors. By winning prestigious literary honors such as the Booker and Pulitzer prizes, IWE have substantiated the claim of Indians on English that has been 'reterritorialized' in true sense.

\section{Bollywood ${ }^{7}$}

In the history of 100 years of Indian cinema, the dynamics of Hindi and English has been subject to various socio-political forces acting upon both languages. The usage of English has invariably served as the signifier of 'Englishness,' a combination of westernized, non-Indian and alien attitude, usually resented or mocked at through villainous, upper-middle class or comical characters. The negative associations with English continued roughly up until 1990s after which Hindi cinema opened up to its own English speaking NRI audience. English could not be seen as the language of outsiders anymore, as it was being spoken by PIOs and natives alike. The changed mood of the nation wad reflected through the changed stance of Bollywood towards English, which now attempted to fuse English and Hindi by bringing them out of their water-tight compartments. This merger created new social meanings, and Hinglish became a common space to be inhabited by both Hindi and English.

Today, Bollywood speaks a very colloquial lingo, an informal register in a liberal mix of Hindi and English. But this was not so earlier in the 1960s and 1970s, when

\footnotetext{
${ }^{6}$ Shobha Rajadhyaksha, also known as Shobhaa De, is an Indian columnist and novelist. De is best known for her depiction of socialites and sex in her works of fiction, for which she has come to be known as the "Jackie Collins of India". (Source: Wikipedia).

${ }^{7}$ Bollywood is the sobriquet of the Hindi language film industry, based in Mumbai, India. Bollywood is one of the largest film producers in India and one of the largest centres of film production in the world. It is more formally referred to as Hindi Film cinema. The name "Bollywood" is a portmanteau derived from Bombay (the former name for Mumbai) and Hollywood. Though some deplore the name, arguing that it makes the industry look like a poor cousin to Hollywood, it has its own entry in the Oxford English Dictionary. (Source: Wikipedia)
} 
the villain Ajit would mouth Hinglish dialogues, like Mona darling, where is the sona? Or upper middle class heroines like Nadira would spume shut up and get out, gandi nail ke keede. These situations always evoked resentment towards these characters that was directly associated with language and social class. Later in the 1975 blockbuster Sholay, when a character named Veeru attempts to commit suicide after failing to impress his beloved's aunt, he slurs in Hinglish under the effect of alcohol producing a very comical effect.

When I dead, police coming, police coming, budhiya going jail, and chakki peesing.. and peesing.. and peesing ... (G.P. Sippy 1975)

(when I die, police is going to arrive, when police arrives, this old hag will go to jail and would labor on the grindstone)

With English occupying a not-so-alien status after the entry of Hinglish on the Indian mindscape, the scenario also changed in Bollywood movies. The predominance of Hinglish in Indian cinema began with songs like Keh do na keh do na, you are my Sonia serving as a rough marker of its arrival. After which the invasion of Hinglish was rapid and widespread as it vehemently made its way into the titles, dialogues and lyrics of the movies in a big way. This was initially seen as a bid to woo its diasporic audience post the 1995 blockbuster Dilwale Dulhaniya Le Jayenge, which was a huge blockbuster worldwide. But soon movies resonated with, as Rita Kothari puts it, 'funon-Indian-terms.' (R. Kothari 2011) The 'youngistaan' wanted things spiced up the Indian way and hence Dard-e-disco or chance pe dance was lapped up easily. As the trends, choices and style of the youth changed, so did the songs and titles with contrasted or compromised Hindi and English.

English Vinglish, Dear Zindagi, Apna Sapna Money Money, Jab We Met; Love Aaj Kal; Thoda Pyaar Thoda Magic; Desi Boys; Pyar Mein Twist; Shaadi Ke Side Effects; Shuddh Desi Romance

The 2007 mega hit Jab We Met can be dubbed as a total Hinglish movie without any conscious effort to being so. Its title as well as dialogues, such as the one given below, gives the accurate glimpse of the language employed in everyday social participation in India.

Mera record hai aaj tak ka, kabhi train nahi chooti, thank you babaji, mujhe non a/c mein zyada achcha lagta hai par meri family kehti hai ki akeli ladki ko non a/c mein travel nahi karna chahiye! (D. Mehta 2007)

These Hinglish lines between the two main characters reflect the naturalness and ease of conversation that serves as the true representation of present generation's communication style. There is ease in the mish-mash jargon that openly flouts the linguistic norm of either language. Contemporary Bollywood is celebrating Hinglish like never before. It has found a language that offers enough scope for neutrality that is much preferred to bring a diversified audience together on a common viewership level. Here are a few lines from typical Hindi movie songs of today that represent the chequered sentiments of the present generation in an equally chequered language. 
1. Ladki beautiful kar gai chull ${ }^{8}$ (beautiful chic is such a tease)

2. But pappu can't dance saala... (Bloody pappu can't dance)

3. Tere liye hi toh signal tod tad ke, aaya dilli wali girlfriend chod chad ke... ${ }^{10}$ (For you, I've come here breaking all the traffic signals, breaking off with my Delhi based girlfriend)

4. Golmaal, golmaal, everything's gonna be golmaal... ${ }^{11}$ (chaos, everything is gonna be chaos)

5. Oh Womaniya, aha womaniya... ${ }^{12}$ (the suffix iya added to noun woman is merely for Bhojpuri ${ }^{13}$ effect)

6. Panghat pe aake saiyan, chede kanhaiyan, and everybody blames it on Radha... ${ }^{14}$ (the beloved Kanhaiya comes on the river bank, teases all, and everybody blames it on Radha ${ }^{15}$ )

Baffled by the pure Hindi text of the script, Maine azaadi se shaadi kar li hai, a Delhi based young man in the film Rang De Basanti asks, 'who talks like this now?' (R. O. Mehra 2006) This kind of irreverence sums up the attitude of present generation of Bollywood as well as the youth who have become so comfortable in this particular linguistic space that a pure Hindi or, for that matter, pure English line comes across as an anomaly and jarring dissonance.

\section{Advertising}

Advertising has played a pro-active role in the production and dissemination of Hinglish as the new lingua franca of the nation. The surge of MNCs riding the wave of globalization and economic liberalization has made the advertising world ever more competitive and creative. With the infiltration of every new company and the introduction of every new product in the consumer-oriented market, the ad world seeks to seize the attention of the consumer with sharp, crisp and cutting edge advertising campaigns, slogans, tag lines, jingles that keep the target hooked to the ad, if not to the product. Hinglish comes in handy here again. Consider the tag lines of some of these famous ads:

Pepsi - yehi hai right choice baby! Aha...(This is the right choice baby)

Maggie- taste bhi health bhi (taste also, health also)

Snickers- jab hunger machaye shor, snickers khol (when hunger makes noise, open up snickers)

ICICI banks- no chinta only money (no tension, only money)

Navratna oil- thanda thanda cool cool (thanda is Hindi for cool)

\footnotetext{
${ }^{8}$ Movie: Kapoor \& Sons Since 1921 (2016).

${ }^{9}$ Movie: Jaane Tu Ya Jaane Na (2008).

${ }^{10}$ Movie: Yeh Jawani Hai Diwani (2013).

${ }^{11}$ Movie: Golmaal Returns (2008).

12 Movie: Gangs of Wasseypur (2012).

${ }^{13}$ Bhojpuri is one of the dialects of Hindi spoken in north, north-eastern parts of India.

${ }^{14}$ Movie: Student of the Year (2011).

${ }^{15}$ The song is the modern expression of Indian mythological love songs of Krishna-Radha.
} 
Virgin mobiles- think hatke (think different)

(Source: All taglines taken from various sources on Internet)

These are just a few of the many ad lines that are visible in videos, audios, posters and prints. It would not be wrong to argue that Hinglish is 'the rule' in advertisements. It has emerged as a powerful 'idea' that has revolutionized the way marketing is done and ads are conceptualized. It seems to be the best way to make a slogan catchy among the masses. For example, one of the leading brands in dairy products, Amul, owes much of its popularity to its creative marketing team. This marketing team has always been successful in connecting a very topical issue with its product's quirky tag line achieved through some very ingenious phraseology. Print and e-media is filled with all kinds of ads in Hinglish that are innovative, intelligent, funny, subtle and poignant, sometimes overriding the product itself. The product goes out of the market but the slogans or jingles remain fresh in memory. Embedded deeply into the subconscious, Hinglish plays an important role in re-defining and modifying the mass-culture components and its subsets in a very subtle yet definite manner. One of the recent ads of a famous online store Snapdeal showcases the attitude of ad-world and the viewers towards the much sought after language. It has turned out to be the 'dilki deal,' for both makers as well as target viewers of the commercials where they can negotiate the salability of the product on the terms that are viable and acceptable to everyone. These mixed up slogans not only add to the brand value of the product but also to the promotion of the Hinglish language.

\section{Conclusion}

In the times of compulsive social networking, the codes and norms of success have changed. In this age, people seek validation and acceptance to feel normal and secure. The present generation lives by the hashtags, likes and dislikes on the walls/handles of Facebook and Twitter, hung upon the idea of keeping up with what is trending. In order to possess a cool yet swish and swanky vibe, Hinglish offers people symbols of success, relevance and modernity. Keeping up with the times is an important driving force compelling most literate Indians to become users of English, or at least Hinglish which works like a glossy sheen on Hindi or any other native tongue. The fusion that emerges out of this liberal hybrid is intriguing and fascinating to most of the language researchers in India. Despite a considerable increase in its usage, English is still generally regarded as a measure of one's achievements and success. In a status-riddled society like India, the use of English, and to some extent now Hinglish, spells class, sophistication, upward mobility and higher eminence.

One concern about the shift into greater usage of Hinglish is the purists' concerns about the 'dangerous Creolization' of the language. These language purists worry that ultimately both Hindi and English will go the Creole way, i.e. become pidgin and will be robbed of their original flavor and nature, leaving the byproduct Hinglish behind in circulation. The onslaught of Hinglish at every communication front has left the standard language supporters fuming over the tempering and corruption happening to Hindi and English. Harish Trivedi in his foreword to Chutnefying English finds the trend disturbing, as he feels doubtful that a jargon like Creole or Hinglish can 
'facilitate serious engagement of any kind, or expression of any intellectual enquiry or creative conceptualization.'(R. Kothari and R. Snell 2011: xxiii) To these critics of Hinglish, it is a matter that calls for a necessary debate. Mahesh Bhatt, renowned filmmaker expresses the importance of allegiance to one's mother tongue saying,

It is only when I spoke my mother's tongue and understood the poetry of Kaifi Azmi and Faiz, Iqbal and Ghalib that I came into my own. So let's not reject that legacy. It is the repository of our creativity, and I would be sad to see it go.” (R. Kothari/ R. Snell 2011: 180)

On the other hand, there are the advocates of Hinglish who see it as a 'celebratory language' of the nation, a natural development process in coexisting languages. It is the lingo that is functional and all pervasive in present day India. For Tej Bhatia, it works towards 'optimizing or neutralizing the paradoxical elements of both the languages' (R. Kothari/ R. Snell 2011: 38). The bilingual individual is able to access his or her vast repertoire of input languages to keep optimizing the linguistic experience by mixing just the right kind and quantity of expressions. This definitely gives the bilingual an edge over a monolingual who does not have this benefit and dwells in mono language system. It is also a fact that languages spoken on a large scale undergo modifications and transformations, and only those languages that elicit flexibility experience longevity. There cannot be a better illustrator of this than English. Rigid languages meet the fate of Latin or Sanskrit. Language that appeals to the heart is spoken most, and as long as it serves the purpose of effective and evocative communication, it stays in circulation. Now whether Hinglish is an attitude, an added style or a permanent register, a marker of identity or just another link in the process of ongoing democratization, is still to be determined.

\section{References}

Das, G. (2005), English How Cool! In: Yale Global Online, Date of access: 29.03.2016. $<\mathrm{http}: / /$ gurcharandas.org/p/65>

Ezekiel, N. (1982), The Patriot. Latter-Day Psalms. allpoetry.com., Date of access: 29.03.2016 https://allpoetry.com/poem/8592073-The-Patriot-by-Nissim-Ezekiel

Gera, A.R. (2013), The Politics of Hinglish. In: L. Wee et al. (eds.), The Politics of English: South Asia, Southeast Asia and the Asia Pacific. Amsterdam.

Kipling, R. Gunga Din. In: L. Untermeyer (ed.), Modern British Poetry. Date of access: 29.03.2016. http://www.bartleby.com/103/48.html

Kothari, R./ R. Snell (ed.) (2011), Chutnefying English: The Phenomenon of Hinglish. Gurgaon.

Mehra, R.O./ R. Screwvala / R.O. Mehra (2006), Rang de Basanti. India: Rakesh Omprakash Mehra Pictures.

Mehta, D. / I. Ali (2007), Jab We Met. India: Shri Ashtavinayak Films.

Mukherjee, M. (2003), 'Introduction', Rushdie's Midnight's Children: A Book of Readings. New Delhi.

Sippy, G.P. / R. Sippy (1975), Sholay. India: United Producers \& Sippy Films.

Verghese, P.C. (1971), Problems of Indian Creative Writers. Somaiya Publications. 
Yule, H. / A.C. Burnell (1903), Hobson-Gobson: a Glossary of Anglo-Indian Colloquial Words and Phrases and of Kindred Terms, Etymological, Historical, Geographical and Discursive. Date of access: 29.03.2016. https://archive.org/stream/hobsonjobsonglos00yulerich\#page/n9/mode/2up 